\title{
Online characterization of nano-aerosols released by commercial spray products using SMPS-ICPMS coupling
}

\author{
Sabrina Losert • Adrian Hess • \\ Gabriele Ilari • Natalie von Goetz • \\ Konrad Hungerbuehler
}

Received: 15 December 2014 / Accepted: 13 June 2015

(C) Springer Science+Business Media Dordrecht 2015

\begin{abstract}
Nanoparticle-containing sprays are a critical class of consumer products, since human exposure may occur by inhalation of nanoparticles (NP) in the generated aerosols. In this work, the suspension and the released aerosol of six different commercially available consumer spray products were analyzed. Next to a broad spectrum of analytical methods for the characterization of the suspension, a standardized setup for the analysis of aerosol has been used. In addition, a new online coupling technique (SMPSICPMS) for the simultaneous analysis of particle size and elemental composition of aerosol particles has been applied. Results obtained with this new method were confirmed by other well-established techniques.
\end{abstract}

Electronic supplementary material The online version of this article (doi:10.1007/s11051-015-3078-2) contains supplementary material, which is available to authorized users.

S. Losert · A. Hess

Laboratory for Analytical Chemistry, Empa Swiss Federal Laboratories for Materials Science and Technology,

Überlandstrasse 129, 8600 Dübendorf, Switzerland

S. Losert · N. von Goetz $(\bowtie) \cdot$ K. Hungerbuehler Institute for Chemical and Bioengineering, ETH Zürich Swiss Federal Institute of Technology Zürich, VladimirPrelog-Weg 1, 8093 Zürich, Switzerland e-mail: natalie.von.goetz@chem.ethz.ch

G. Ilari

Electron Microscopy Center, Empa Swiss Federal Laboratories for Materials Science and Technology,

Überlandstrasse 129, 8600 Dübendorf, Switzerland
Comparison of particles in the original suspensions and in the generated aerosol showed that during spraying single particles of size less than $20 \mathrm{~nm}$ had been formed, even though in none of the suspensions particles of size less than $280 \mathrm{~nm}$ were present (Aerosol size range scanned: 7-300 nm). Both pump sprays and propellant gas sprays were analyzed and both released particles in the nm size range. Also, both water-based and organic solvent-based sprays released NP. However, a trend was observed that spraying an aqueous suspension contained in a pump spray dispenser after drying resulted in bigger agglomerates than spraying organic suspensions in propellant gas dispensers.

Keywords Nanoparticles · Nano-spray - spICPMS · TEM $\cdot$ SMPS $\cdot$ Inhalation exposure

\section{Introduction}

The number of nanoparticle-containing consumer products increased over the last 10 years from a few to several hundreds and their number is expected to further increase in the future (Woodrow Wilson 2012). Market surveys identified silver (Benn et al. 2010; Chen and Schluesener 2008; Kaegi et al. 2010), zinc oxide (Graf et al. 2013), titanium dioxide (Skocaj et al. 2011), carbon and silica (Zhu et al. 2010) as the species that are most frequently used as nanoparticles 
(NP) in consumer products such as textiles, food and food storage, cosmetics (e.g., sprays), household chemicals (e.g., paints, sprays), or sports equipment (Al-Kattan et al. 2013; Brzeziński et al. 2012; Hall et al. 2007; Lorenz et al. 2012; von Goetz et al. 2013; Xue et al. 2012).

Sprays that contain NP were identified as the most critical class of consumer products due to their direct exposure pathway via lungs, which implies an enhanced health risk (Krug and Wick 2011; Nørgaard et al. 2010; Schneider et al. 2011; Sung et al. 2008;). During the last years, first studies on nanoparticlecontaining sprays and associated nanoparticle exposure were published (Chen et al. 2010; Hagendorfer et al. 2010; Lorenz et al. 2011; Oomen et al. 2011). In some of these studies, the original spray suspensions were investigated (Hagendorfer et al. 2010; Lorenz et al. 2011). Information was collected about the following four important properties: particle size, chemical composition (of the particles and the whole suspension), particle number concentration, and shape. However, thus far, no analytical technique is available that informs about all these parameters at the same time. Particle shape, size, and chemistry can be determined offline via electron microscopy (SEM/ TEM), which is very time consuming and costly. Size can also be determined online via dynamic light scattering (DLS), which, however, is not very precise for polydisperse samples, as the larger particles are overestimated and measured particle size is always larger than it really is. Bulk analysis of the chemical composition and concentration can be done by inductively coupled plasma mass spectrometry (ICPMS) after the digestion of a sample, which is very time consuming and requires a high level of sample preparation.

New promising techniques for suspension analytics investigate at least two or three of the desired four parameters. Via single-particle inductively coupled mass spectrometry (spICPMS), particle size and number concentration can be measured, if the elemental composition is known and spherical particles can be assumed. This technique is extremely fast (a few seconds) and can be performed with most of the conventional ICPMS instruments (older instruments, however, may not have the adequate acquisition time). Second, asymmetric flow field-flow fractionation (A4F) can provide information on the particle size distribution (PSD), coating of the particles and, when coupled to ICPMS, also on the chemistry and the concentration (Berlin et al. 2011).

For the analysis of the nanosized particle fraction generated by sprays, analytical techniques need to be used that are different from the techniques used for the suspension. To date the following techniques have been used for nanoparticle analysis in aerosols: PSD and number concentration have been measured online by scanning mobility particle sizer (SMPS) (Berlin et al. 2011; Hagendorfer et al. 2010; Lorenz et al. 2011; Quadros and Marr 2011) or fast mobility particle sizer (FMPS) for particles in the size range of 10-500 nm (Chen et al. 2010; Losert et al. 2014; Nørgaard et al. 2009; Oomen et al. 2011). However, with SMPS or FMPS, it is not trivial to differentiate between droplets and solid particles, and in many studies only droplet sizes have been determined. Size and shape of particles have been identified offline by prior sampling on TEM grids and analysis by TEM (Bekker et al. 2014; Hagendorfer et al. 2010; Lorenz et al. 2011; Quadros and Marr 2011), and the aerodynamic diameter of larger particles between $300 \mathrm{~nm}$ and $20 \mu \mathrm{m}$ online by aerodynamic particle sizer (Nørgaard et al. 2009). The chemical identity of particles was determined by EDX coupled to TEM or SEM. Currently no technique is available that provides information on all properties simultaneously. Instead, properties of a sample have to be determined with online and offline techniques at the same time, which means that the sampled aliquot may differ between techniques. For example, PSD and number concentration can be measured online and time resolved, whereas shape and chemistry need to be identified offline with TEM-EDX after sampling on a TEM grid over a longer period of time.

In this work, a new promising coupling technique, SMPS-ICPMS, was used to analyze the aerosol of six commercially available sprays concerning PSD, number concentration, and elemental composition. Simultaneously, these properties were determined by other established methods in order to assess the performance of the new coupling technique. Furthermore, spICPMS was applied for characterizing the suspensions and compared to conventional methods such as DLS and scanning electron microscopy (SEM).

A standardized spray setup was employed that simulates worst-case consumer exposure. To meet worst-case conditions, particle number concentration and the PSD of pump and propellant gas sprays were 
monitored at a defined position inside a spray chamber. This position had been identified to be the worst case for most spray applications. For good comparability among the experiments, the duration and direction of spraying had been predefined.

\section{Experimental section}

\section{Selection of products}

The aim was that the selection be most representative of the range of consumer spray products with NP on the market. The first criterion was that the manufacturer should have labeled the product with "nano". Second, since the composition of the aerosol depends on the spraying device and the formulation, we considered different vessel types, different solvents, and different intended uses (Losert et al. 2014). Thus, a broad spectrum of sprays was covered that included cosmetic sprays as well as impregnation sprays (used to render a material dirt or water repellant), and different types of NP. The six different spray products, which were selected for this study, are listed in Table 1.

\section{Standardization of exposure experiments}

Spray experiments were conducted in a spray chamber with a volume of $0.33 \mathrm{~m}^{3}$, representing the near breathing zone of a consumer. Spray vessels were always positioned at a distance of $30 \mathrm{~cm}$ to the outlet of the chamber. The average arm length of a Swiss resident was calculated to be $57 \mathrm{~cm}$ (woman and man) (Bammes 2001; FORS COMPASS 2014; Rühli et al. 2008; Statistisches Bundesamt 2009). As some sprays are applied with outstretched arms and others with bent arms, the chosen distance of $30 \mathrm{~cm}$ should represent a reasonable worst-case scenario.
Spraying was directed toward the outlet. The spray duration was always the same for each spray. Propellant gas sprays were sprayed for $3 \mathrm{~s} ; 3$ pump strokes were applied for pump spray dispensers.

\section{Experimental setup}

The six nanoparticle-containing consumer sprays were analyzed for their chemical composition and PSD. The suspension was analyzed by ICPMS, spICPMS, DLS, and SEM. The aerosol was released by spraying inside a modified glove box setup with integrated analytical devices (Hagendorfer et al. 2010). Based on the considerations by Losert et al. (2014), the spray direction, spray duration, and the distance of the vessel to the measurement device were precisely defined for the spraying procedure.

Before each experiment, the background of the chamber was measured and after each experiment, the chamber was flushed with fresh air. The next experiment was performed when the background was again at the same level as at the beginning of the preceding experiment.

Throughout the measurements, the relative humidity and the temperature were monitored. Humidity did not exceed 50 and $60 \%$ for propellant gas sprays and pump sprays, respectively. During the experiment, an almost constant temperature of $21{ }^{\circ} \mathrm{C}$ was measured. The spray chamber was connected to a modified SMPS coupled to a commercial ICPMS to determine online the size distribution and size-resolved elemental composition. The SMPS, consisting of a differential mobility analyzer (DMA) followed by a condensation particle counter (CPC), first selected one particle size fraction from the heterogeneous aerosol and then determined the number concentration of particles contained in this fraction by condensationdriven particle growth and subsequent optical detection. By varying the selected size fraction, a particular
Table 1 Selected consumer sprays

n.m. NP type not mentioned on the label; but labeled as a "nano product"

\begin{tabular}{llllll}
\hline & Vessel type & Solvent & Application & Target medium & NP type \\
\hline Spray I & Pump & Water & Cosmetic spray & Human skin & Ag \\
Spray II & Pump & Water & Impregnation spray & Glass & n.m. \\
Spray III & Propellant & Water & Impregnation spray & Glass, Ceramic & n.m. \\
Spray IV & Propellant & Alcohols & Impregnation spray & Textiles & n.m. \\
Spray V & Propellant & Silicones (1) & Antiperspirant & Human skin & Ag \\
Spray VI & Propellant & Alcohols & Sunblock & Leather, Textiles & n.m. \\
\hline
\end{tabular}


particle size ratio was scanned for $120 \mathrm{~s}$ and the instrument was ready for the next scan another $60 \mathrm{~s}$ later. The ICPMS ionized the particles and detected the mass-to-charge ratio. Thus, the elemental composition of the particles of each size class could be identified. A detailed explanation of this technique is given by Hess et al. (2015).

The shapes of the particles were determined by applying electron microscopy: a TEM sampler was connected to the spray chamber to collect samples for these offline analysis techniques. Also a non-modified reference SMPS was connected to the spray chamber to validate the results obtained by the coupled instrument. A rotating disk dilutor (RDD) was positioned at the inlet of each SMPS instrument and served as sample introduction interface and heated dilution unit (see Fig. 1). The RDDs were heated to $80{ }^{\circ} \mathrm{C}$, so that the solvent droplets were evaporated and only the solid particles could enter the measuring instrumentation. Conductive tubing was used for all connections from the spray chamber to the instruments and also within the instruments to minimize electrostatic particle losses at the tubing walls.

\section{Chemicals}

Nitric acid $(65 \% \mathrm{w} / \mathrm{w})$ and hydrochloric acid $(30 \% \mathrm{w} / \mathrm{w})$ were purchased in suprapure quality and hydrogen peroxide $(31 \% \mathrm{w} / \mathrm{w})$ in pro-analysis quality from Merck (Merck GmbH, Darmstadt, Germany). ICPMS multi-element standard Merck VI (110580, Merck GmbH, Darmstadt, Germany) and single element standards of $1 \mathrm{~g} / \mathrm{L} \mathrm{Au}, \mathrm{P}, \mathrm{Pt}, \mathrm{S}, \mathrm{Si}, \mathrm{Sn}, \mathrm{Ti}$ (Specpur, Alfa Aesar GmbH \& Co KG, Karlsruhe, Germany) were freshly diluted with deionized water before each measurement. For the production of deionized water $(18 \mathrm{M} \Omega \mathrm{cm})$, a Millipore, Milli-Q A-10 water unit (Millipore AG) was used. The single

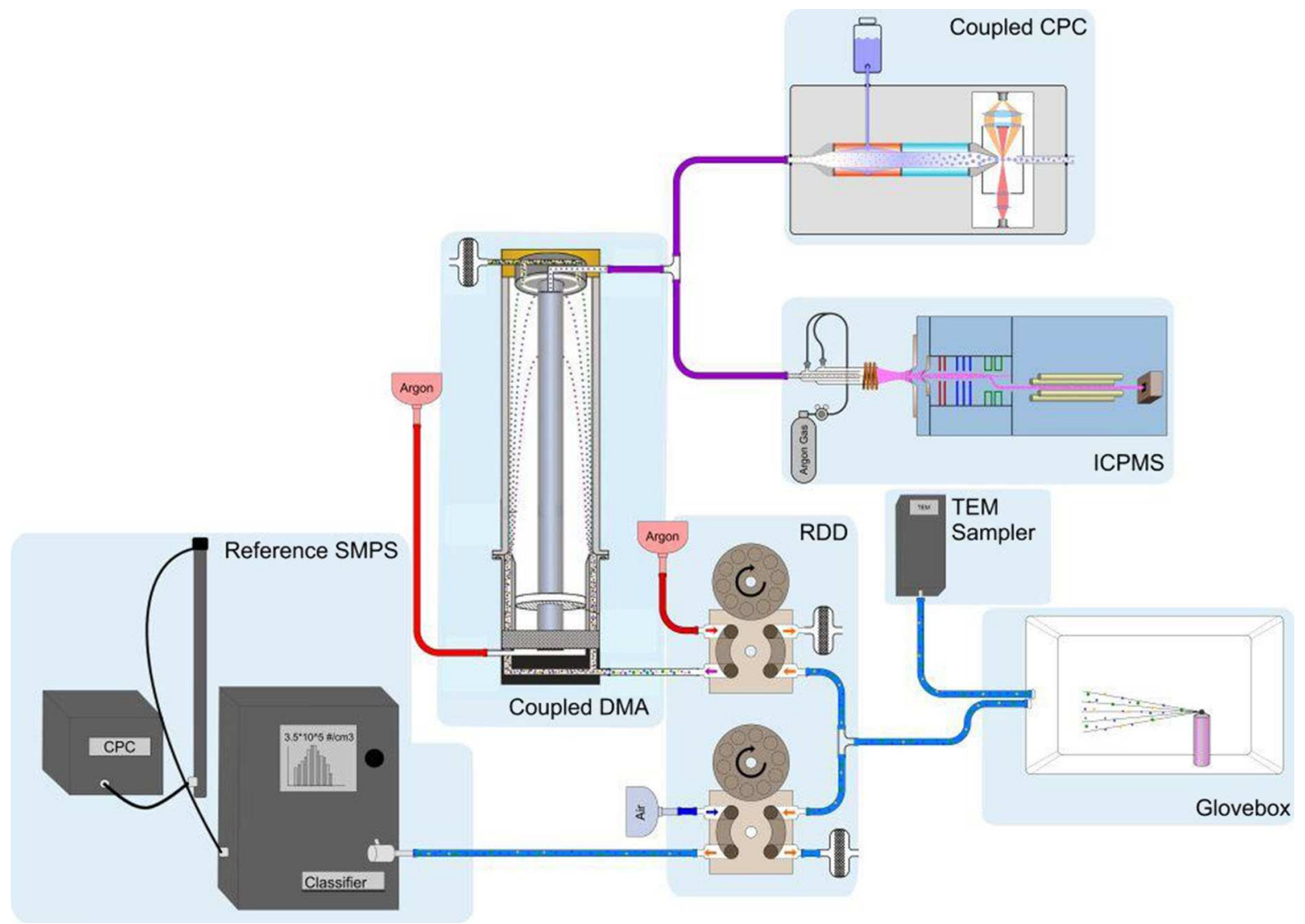

Fig. 1 Experimental setup for aerosol analysis. Right to left spray chamber connected to the TEM sampler and two RDDs-one leading to the reference SMPS, one to the coupled DMA. After the DMA, the stream is split between CPC and ICPMS 
element and multi-element standards were always freshly diluted before each measurement.

Suspension analysis

For the suspension analysis, the spray cans were cooled with liquid nitrogen for $15 \mathrm{~min}$. Then they were opened and left over night to let the organic solvent and the expanding propellant gas evaporate. The next day one part of the suspension was digested completely by microwave digestion for subsequent total elemental analysis and another part was diluted for nanoparticle analysis. The digestion method was adapted to each spray product depending on its labeled composition and observations during the digestion process. For the digestion of product I, $6 \mathrm{~mL}$ nitric acid and $2 \mathrm{~mL}$ hydrochloric acid were added to an aliquot of $200 \mu \mathrm{L}$. For products II and IV, $2 \mathrm{~mL}$ nitric acid and $6 \mathrm{~mL}$ hydrochloric acid were added to an aliquot of $200 \mu \mathrm{L}$. For products III, V, and VI, $3 \mathrm{~mL}$ nitric acid and $1 \mathrm{~mL}$ hydrogen peroxide were added to an aliquot of $50 \mu \mathrm{L}$. After microwave digestion $\left(220{ }^{\circ} \mathrm{C}, 30 \mathrm{~min}\right)$, a clear solution was obtained. The digests were transferred to PE vessels and filled up with DI water to $50 \mathrm{~mL}$. Suspension ICPMS analysis was carried out on an Agilent 8800 ICPMS (Agilent Technologies, Waldbronn, Germany) using an external calibration adjusted against Scandium, Germanium, and Rhodium as internal standards. The instrument was equipped with two quadrupole analyzers (MS/MS) and a collision/reaction cell. The limit of detection was calculated as three times the standard deviation of the background signal.

The diluted, non-digested samples were analyzed via batch DLS. Measurements were carried out on a Malvern Zetasizer NanoZS (Malvern Instruments Ltd., Germany). Before analysis, all samples were warmed in the batch cell to $25^{\circ} \mathrm{C}(1 \mathrm{~min})$.

For SEM analysis, the suspensions were centrifuged on "FORMVAR carbon-coated mesh 200 copper TEM grids" (SPI\#3420C, SPI Inc., West Chester, PA, USA). Imaging was done on a Nova NanoSEM 230 (FEI Corporate, Hillsboro, USA). Particles were counted using image analysis software (ImageJ, National Institutes of Health, US).

Single-particle ICPMS measurements were carried out on the same Agilent 8800 ICPMS as the suspension analysis. A dwell time of $5 \mathrm{~ms}$ and a flow rate of $0.24 \mathrm{~mL} / \mathrm{min}$ were applied.
Aerosol analysis

A commercially available Poly(methyl methacrylate) PMMA glove box (Meca Plex, Grenchen, Switzerland) with dimensions of $94 \times 55 \times 67 \mathrm{~cm}$ was modified as described by Hagendorfer et al. (2010). The basic SMPS instrumentation used for coupling to ICPMS included a DMA 3081 (TSI, GmbH, Aachen, Germany) and a CPC 3010 (TSI, GmbH, Aachen, Germany). The aerosol flow rate directed to the CPC was accurately defined with $0.3 \mathrm{~L} / \mathrm{min}$ (Hess et al. 2015). A radioactive source ( $\mathrm{Kr} 85$ aerosol neutralizer 3077A (TSI, GmbH, Aachen, Germany)) was installed at the inlet of the DMA to generate a known charge equilibrium state of the particles. In addition to the coupled SMPS, a reference instrument was used to determine the PSD and particle number concentration. The instrument contained an electrostatic classifier 3080L (TSI GmbH, Aachen, Germany) and an ultrafine condensation particle counter 3776 (TSI GmbH, Aachen, Germany). The modified coupled SMPS was able to scan a particle size ranging from 7.5 to $156 \mathrm{~nm}$, the reference instrumentation from 7 to $300 \mathrm{~nm}$.

The same Agilent 8800 ICPMS was used for the SMPS-ICPMS coupling. The sampling introduction system was removed. The DMA was operated with $1.0 \mathrm{l} / \mathrm{min}$ sample flow, being split at the DMA outlet, and a $0.7 \mathrm{l} / \mathrm{min}$ fraction was directed to the ICP torch.

Aerosol samples were collected on TEM grids using a portable nanoparticle detector, which were sampled on standard TEM grids by electrostatic precipitation (Partector TEM sampler, Naneos particle solutions $\mathrm{GmbH}$, Windisch, Switzerland). TEM images were acquired on a JEOL 2200 microscope operated at $200 \mathrm{kV}$.

\section{Results}

Suspension

\section{Total chemical analysis}

Figure 2 shows the concentration of metals determined after digestion and total elemental analysis of the spray suspensions. All suspensions showed peaks for $\mathrm{Al}$ and $\mathrm{Fe}$. These most probably originate from the spray cans. Apart from these, suspension I contained only silver $(18.1 \mu \mathrm{g} / \mathrm{L})$ and zinc $(52.6 \mu \mathrm{g} / \mathrm{L})$ in higher concentrations. In suspension II, tin was found in the 
Fig. 2 Metal concentrations in the investigated commercial spray suspensions

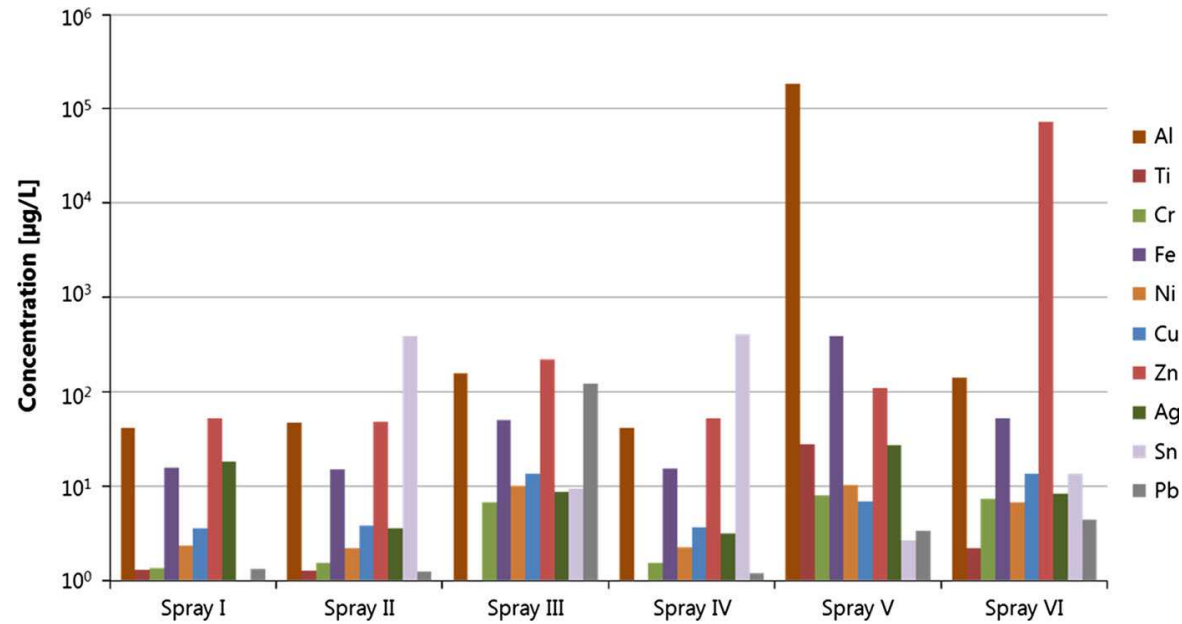

highest concentration of all investigated elements (395 $\mu \mathrm{g} / \mathrm{L})$. Suspension III contained high concentrations of zinc $(224 \mu \mathrm{g} / \mathrm{L})$ and tin $(9.5 \mu \mathrm{g} / \mathrm{L})$. In suspension IV, tin $(413 \mu \mathrm{g} / \mathrm{L})$ and zinc $(52.8 \mu \mathrm{g} / \mathrm{L})$ were found. Suspension V contained the highest concentration of metals: In addition to a high concentration of aluminum $(185,300 \mu \mathrm{g} / \mathrm{L})$, iron $(392 \mu \mathrm{g} / \mathrm{L})$, titanium $(27.9 \mu \mathrm{g} / \mathrm{L})$, and silver $(27.2 \mu \mathrm{g} / \mathrm{L})$ were present. Suspension VI contained a high concentration of zinc $(73,000 \mu \mathrm{g} / \mathrm{L})$.

\section{Particle analysis}

DLS measurements showed that in suspension I, particles of the size $320 \pm 39 \mathrm{~nm}$ were present. In suspension II, particles of $555 \pm 120 \mathrm{~nm}$ were found. For suspension III, the size of the particles was outside the effective range, which was between $0.3 \mathrm{~nm}$ and $10 \mu \mathrm{m}$ (Malvern 2004). Suspension IV contained particles of size $373 \pm 73 \mathrm{~nm}$. For suspension V, DLS analysis was not possible since the residue resisted to dilution after evaporation of the organic solvent. For suspension VI, the size of the particles was outside the effective range.

spICPMS detected Ag particles of $303 \pm 12 \mathrm{~nm}$ for suspension I, and tin particles of $263 \pm 10$ and $244 \pm 37 \mathrm{~nm}$ for suspensions II and IV, respectively. For suspension III, no particles in the nano-range were detected. Consequently, either dissolved tin and zinc ions or very big agglomerates were present in suspension III. The same can be supposed for suspension VI.

SEM images of particles/agglomerates in the original spray suspensions (see Fig. 3) show huge agglomerates of particles in the $\mu \mathrm{m}$ size range for all tested suspensions. For suspension I (Fig. 3a), a three-dimensional agglomerate with the dimensions $6 \mu \mathrm{m} \times 3 \mu \mathrm{m}$ was observed consisting of single particles of size $369 \pm 87 \mathrm{~nm}$. Also for suspensions IV and VI, similarly structured agglomerates were found (Fig. 3d, e). The agglomerate in suspension IV had the dimensions $6.8 \mu \mathrm{m} \times 4.3 \mu \mathrm{m}$, and single particles were of size $205 \pm 31 \mathrm{~nm}$. The agglomerate of suspension VI was $26 \mu \mathrm{m} \times 24 \mu \mathrm{m}$; the single particles were as large as $1700 \pm 250 \mathrm{~nm}$. Particles found in suspension II and III (Fig. 3b, c) were also agglomerated, but the layer of agglomerates on the TEM grid was less thick than for the other three suspensions. Primary particles found in suspension II were $600 \pm 143 \mathrm{~nm}$; primary particles in suspension III were $1000 \pm 400 \mathrm{~nm}$. EDX analysis (see supporting information) agrees well with bulk ICPMS results, with the exception of suspension I (no silver was found with EDX).

In all of the analyzed samples, aluminum was detected with EDX.

A comparison of all results for suspension analysis can be found in Table 2 .

Aerosol

\section{Validation of SMPS-ICPMS data}

With an SMPS being hyphenated to ICPMS (SMPSICPMS) and an additional, non-modified reference SMPS, particle concentrations above the measured particle background signal were measured for all tested sprays apart from sample I. Generally, both 

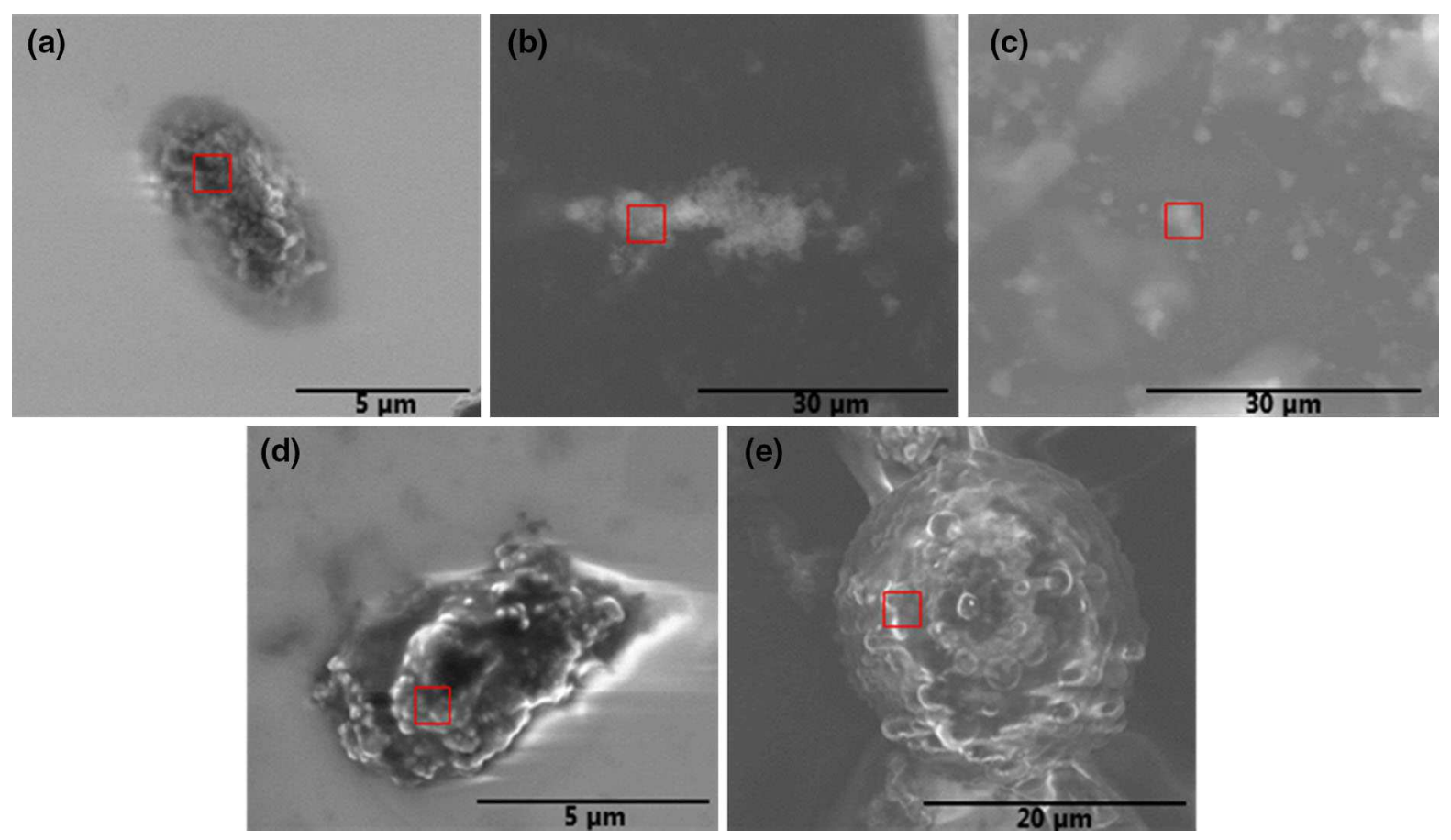

Fig. 3 SEM images of suspensions of a spray I, b spray II, $\mathbf{c}$ spray III, $\mathbf{d}$ spray IV, and e spray VI. Red-shaded areas were investigated by EDX (see SI Figure S1, Color figure online)

Table 2 Characteristics of the investigated spray products (suspensions and aerosols) as determined with different analytical methods

\begin{tabular}{|c|c|c|c|c|c|c|c|c|c|c|}
\hline & \multicolumn{5}{|c|}{ Suspension } & \multicolumn{5}{|l|}{ Aerosol } \\
\hline & \multicolumn{2}{|l|}{ Identity } & \multicolumn{3}{|c|}{ Particle size (nm) } & \multicolumn{2}{|l|}{ Identity } & \multicolumn{2}{|c|}{ Particle size (nm) } & \multirow{2}{*}{$\begin{array}{l}\text { Particle number } \\
\text { SMPS (cpl) }\end{array}$} \\
\hline & ICPMS & EDX & DLS & spICPMS & SEM & ICPMS & EDX & $\begin{array}{l}\text { SMPS } \\
(\mathrm{cpl})\end{array}$ & TEM & \\
\hline Spray I & $\mathrm{Ag}$ & $\mathrm{Al}$ & $320 \pm 39.5$ & $303 \pm 12$ & agg & - & $\mathrm{Ag}, \mathrm{Cl}$ & - & $1350 \pm 270$ & - \\
\hline Spray II & $\mathrm{Sn}, \mathrm{Zn}$ & $\mathrm{Al}, \mathrm{Zn}, \mathrm{F}$ & $555 \pm 120$ & $263 \pm 10$ & agg & $\mathrm{Sn}$ & $\mathrm{Sn}, \mathrm{F}$ & $85 \pm 3$ & $1057 \pm 590$ & $5.5^{*} 10^{5} \pm 4.0^{*} 10^{4}$ \\
\hline Spray III & $\mathrm{Zn}, \mathrm{Sn}$ & $\mathrm{Al}, \mathrm{Si}, \mathrm{F}$ & agg & agg & agg & $\mathrm{Sn}$ & $\mathrm{Sn}, \mathrm{F}$ & $24 \pm 1$ & $330 \pm 20$ & $2.4 * 10^{5} \pm 1.2 * 10^{4}$ \\
\hline Spray IV & $\mathrm{Sn}, \mathrm{Zn}$ & $\mathrm{Al}, \mathrm{Sn}, \mathrm{F}$ & $373 \pm 73.1$ & $244 \pm 37$ & agg & $\mathrm{Sn}$ & Sn, F & $85 \pm 0$ & $124 \pm 25$ & $5.6^{*} 10^{5} \pm 4.5^{*} 10^{4}$ \\
\hline Spray V & $\mathrm{Al}$ & n.m. & n.m. & n.m. & n.m. & - & $\mathrm{Al}$ & $24 \pm 1$ & - & $3.7 * 10^{5} \pm 1.0 * 10^{4}$ \\
\hline Spray VI & $\mathrm{Zn}$ & $\mathrm{Al}, \mathrm{Zn}, \mathrm{F}$ & agg & agg & agg & $\mathrm{Zn}$ & $\mathrm{Zn}, \mathrm{F}$ & $19 \pm 1$ & $25 \pm 4$ & $4.7 * 10^{5} \pm 1.5^{*} 10^{4}$ \\
\hline
\end{tabular}

For SMPS results the number PSD was used to determine the mean size agg agglomerate

instruments agreed well (see SI Table 1), but the particle sizes measured by the reference SMPS were slightly larger than the sizes measured by the coupled instrument, because the instruments have different delay times due to different tubing lengths (the delay time describes the time a particle needs to travel from the outlet of the DMA to the inlet of the CPC (see Fig. 1)). The particle number concentrations in most cases agreed well for the coupled SMPS, if compared to the reference SMPS.

\section{SMPS-ICPMS setup}

Based on the results from the conventional suspension measurements with ICPMS, sample-specific elements were selected for SMPS-ICPMS aerosol analysis. 
Since for the coupled device the scanning time of the SMPS needs to match the acquisition time of the ICPMS (Hess et al. 2015), only 5 metals could be measured simultaneously and the ICPMS was adjusted to the masses of the metals found in the suspensions.

No increased particle concentrations, in comparison to the background level, were recorded by SMPS after spraying of spray I, which was one of the two pump sprays (see diagram in Figure S3a). The particles found in the second pump spray, spray II, had the highest mean diameter of all investigated products. Nevertheless, we could observe a release of NP also from pump spray dispersers. Among propellant sprays, the mean particle diameter in spray IV was about 3.5 times higher than those in the other three sprays. The originally number-weighted PSD determined by SMPS was transformed into a volumeweighted curve, in order to be comparable to the massrelated ICPMS data. As an approximation, spherical particles were assumed for this data conversion.

Figure $4 a-c$ illustrates on the left the volumeweighted PSD, and the size-resolved ICPMS signal intensity, and on the right the number-weighted PSD, determined by the hyphenated SMPS-ICPMS instrumentation. SMPS data are represented as gray-dashed lines, scaled at the left, ICPMS intensities as straight black curves, scaled at the right.

Since the ${ }^{118}$ Sn ICPMS curve agrees very well with the PSD determined by SMPS (see Fig. 4a,b), SMPSICPMS demonstrated that the particles found in sprays II and IV were mainly consisting of tin.

Figure 4c illustrates the average SMPS signal of spray VI and the zinc ICPMS signal of the same spray. The SMPS signal of spray VI and the zinc ICPMS show a similar trend for the volume-weighted PSD: an increase in the zinc concentration can be observed for sizes above $80 \mathrm{~nm}$. Around this size (70-90 nm), the curves of the number-based SMPS and the corresponding ICPMS signal fit quite well. This observation hazards the guess that particles present in sample VI consist not only of zinc but also of another element, which could not be identified by the coupled device. Note that after the conversion of volume-weighted (Fig. 4c, left side) to number-weighted concentration (Fig. 4c, right side, conversion equation, see Supporting Information, Figure S4), the smaller particle sizes are emphasized. Since health effects are mostly associated with single particles, for NP often the number-based concentrations are the preferred unit.
Also for sprays III and V, SMPS signals were found, which could not completely be matched to an ICPMS signal (see SI Figure S4). Therefore, the TEM-EDX measurements were consulted to identify the chemical identity of the aerosol. Spray I did not evoke an SMPS and the corresponding ICPMS signal, but with bulk ICPMS Ag was found in the suspension. Therefore, with EDX it was further investigated, whether $\mathrm{Ag}$ in particular form was present in the aerosol (see below).

\section{Comparison of online measurements with TEM}

TEM images of NP released from the different sprays are displayed in Fig. 5 (red squares $=$ area of EDX found in SI).

No nanometer-sized particles had been detected in the aerosol of spray I by SMPS. This was confirmed by TEM analysis, but a $1.35-\mu \mathrm{m}$ agglomerate was detected, consisting of primary particles with a size of about $30 \mathrm{~nm}$. Smaller particles were observed, which are arranged in a ring-shaped area surrounding the big particle. These smaller particles did not contain metals, but organic compounds (see EDX results in Supporting Information Figure S2). The primary particles inside the agglomerate were identified as silver particles. Summing up, there were primary silver particles in the $\mathrm{nm}$ size range. These were agglomerating very fast and the resulting structures were above the SMPS-ICPMS measuring range, and/ or the primary particles were shielded by organic compounds and therewith not ionized and detected in ICPMS. No single particles were found from spray II, but two agglomerates of 0.5 - and $1.5-\mu \mathrm{m}$ diameter, respectively, were observed by TEM, with primary NP of around $30 \mathrm{~nm}$ building up these big agglomerates. SMPS, however, produced a signal between 80 and $90 \mathrm{~nm}$. Most probably this finding indicates a shortcoming of TEM analysis, being an offline technique, which requires aerosol sampling over a longer period of time. For most of the analyzed products, 3-6 spray experiments were necessary to deposit enough particles on the TEM grids, especially long sampling times were needed for collecting pump spray aerosol particles. During the time on the grid, the primary particles from spray II may have agglomerated (Hagendorfer et al. 2010; Lorenz et al. 2011). Furthermore, the TEM images show that the bigger agglomerate from spray II was consisting of a tin core 

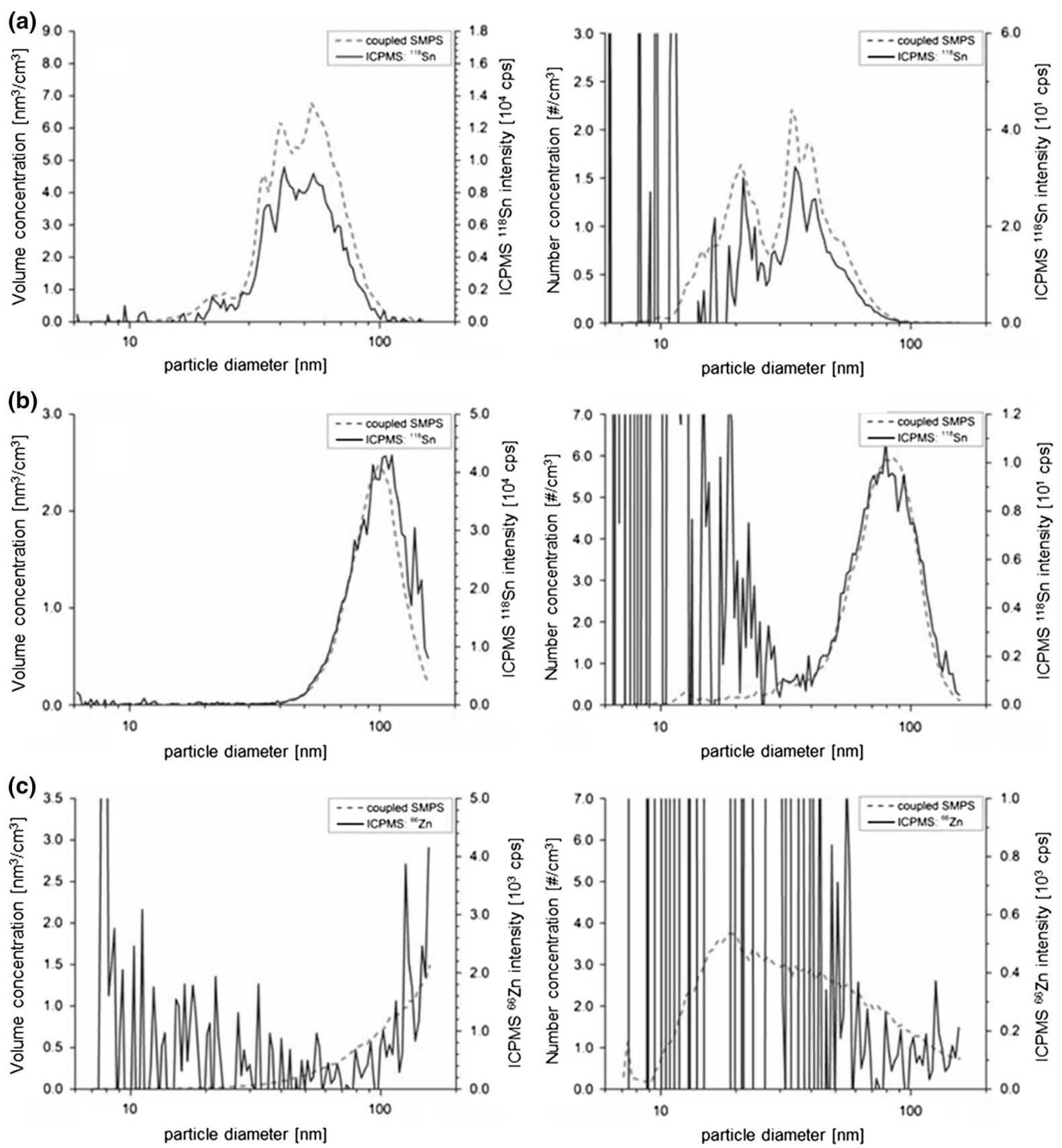

Fig. 4 SMPS-ICPMS results for a spray II, b spray IV, and c spray VI; left volume-weighted PSD, right number-weighted PSD

and a light shell around the core, which mostly consisted of fluorine. For sprays III, IV, and VI, primary particles with mean diameters of 25,85 , and $20 \mathrm{~nm}$ (in the number-weighted PSD), respectively, were found by SMPS. This result could be verified by TEM (Fig. 5c, d, f): All TEM images show primary particles, but agglomeration was observed as well. Via
EDX the composition of the particles was analyzed. NP detected in sprays III and IV contained tin and fluorine. Particles present in spray VI contained also zinc. For spray $\mathrm{V}$, no particles in the $\mathrm{nm}$ size range were detected by TEM: the PSD determined by SMPS and the size-resolved ICPMS intensities recorded in terms of the SMPS-ICPMS online measurements did 

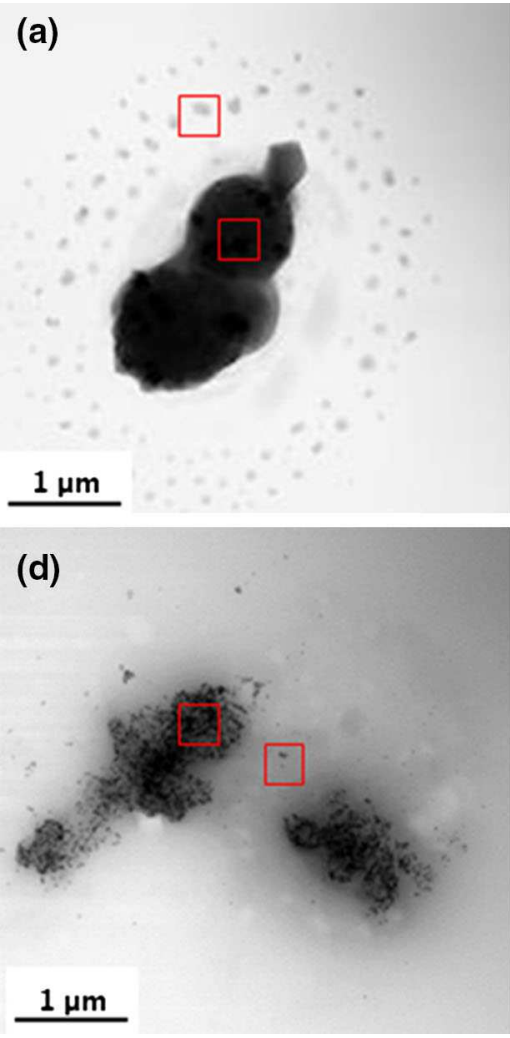
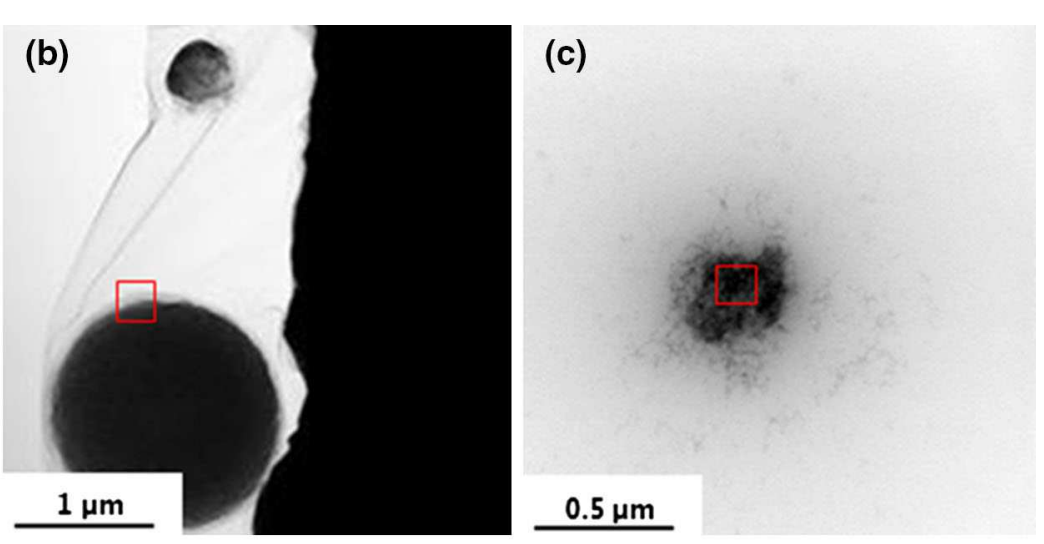

(e)

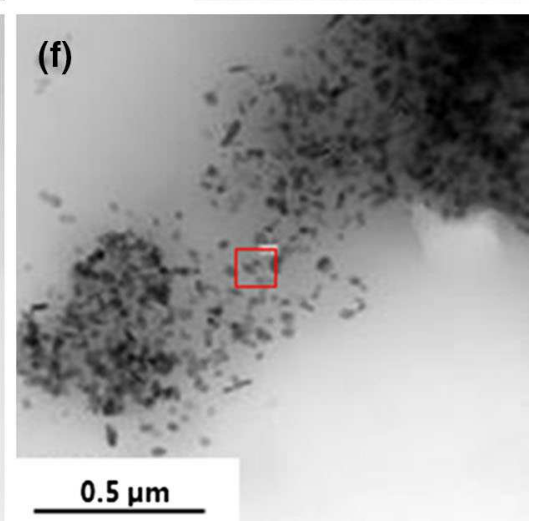

Fig. 5 TEM images of aerosol nanoparticles collected with the TEM sampler after spraying of a spray I, b spray II, c spray III, d spray IV, e spray V, and $\mathbf{f}$ spray VI. (Color figure online)

not match. The particles mainly contain aluminum (determined by EDX).

\section{Summary of suspension and aerosol measurements}

For all investigated products, particle sizes changed due to spraying. With the exception of spray $\mathrm{V}$, all aerosols contained primary particles of size less than $50 \mathrm{~nm}$ (Table 2), even though particles in the suspensions had been larger.

\section{Discussion}

\section{Standardized setup for spray experiments}

Using a standardized spray setup, good reproducibility was achieved (see SI Table 1). Although a larger number of sprays with different applications were tested, results could easily be compared, marking an improvement over previous studies (Berger-Preiß et al. 2005; Nørgaard et al. 2009).
Suspension analysis

\section{Elemental composition}

Product I was labeled with a content of $50 \mathrm{mg} / \mathrm{L}$ silver, but only $18 \mu \mathrm{g} / \mathrm{L} \mathrm{Ag}$ was found with ICPMS analysis of the diluted and digested suspension. As product $\mathrm{I}$ is an aqueous cosmetic spray to be applied on the skin, presumably no acid had been added to the formulation and without acid silver is not stabilized. Hence, the contained Ag may actually have been adsorbed to the vessel walls, so that it was not detectable in the suspension.

In suspensions II, III and IV, tin was found. Tin is typical for impregnation sprays, since they often contain organotin compounds, which are used as accelerators (for faster hardening of the other ingredients) (BgVV 2014). The high aluminum concentration in product $V$ can be explained by the fact that this was an antiperspirant spray. These sprays usually contain high amounts of aluminum to prevent perspiration. 
According to the product label, the aluminum had been added to the product in the form of aluminum chlorohydrate, which had the highest concentration of all product ingredients, apart from the solvents (in Europe ingredients with a concentration $>1 \%$ are listed on the product label in descending order relative to their concentration). The same suspension also contained small concentrations of iron and titanium, which were not labeled, but those elements can be part of so-called alums, being chemical compounds with the formula $\mathrm{AM}\left(\mathrm{SO}_{4}\right)_{2} \cdot 12 \mathrm{H}_{2} \mathrm{O}$, where $\mathrm{A}$ is a cation and $\mathrm{M}$ is a metallike iron or titanium. Alums have antiperspirant and antibacterial effects. For those compounds, no labeling is required, because their concentration is below $1 \%$.

\section{Particle sizes}

Sizes obtained with different methods fit well. Particle diameters determined by spICPMS were smaller than those determined by DLS and SEM, which can be explained by matrix effects: As all samples were simply diluted for spICPMS analysis and the matrix was not removed, probably interferences with the matrix occurred, causing higher background and therewith lower net signal intensity, and finally resulting in smaller calculated particle sizes. Additionally, sprays II and IV contain high amounts of fluorine, which covers the metal NP. As fluorine cannot be ionized in the plasma and subsequently be detected by ICPMS, the calculated particle size is smaller than that obtained from methods that are able to detect fluorine. For sprays III and VI, no particles were found with DLS and spICPMS, whereas SEM allowed observation of agglomerates of 1.0 and $1.7 \mu \mathrm{m}$. Possibly the respective particles got dissolved during the sample preparation for spICPMS and for DLS measurements.

\section{Particle composition}

Silver was found by ICPMS analysis of suspension I, but not via SEM-EDX of the particles, which were sampled from the suspension. This is presumably due to the lower detection limit of the ICPMS, compared to SEM-EDX.

Aerosol measurements

The slight discrepancy between particle number concentrations obtained by coupled SMPS and reference SMPS can be explained with the use of two different rotating disk diluters (RDD). The sampling line included a flow splitter, and each RDD was absorbing about 1 1/min raw aerosol. In the RDD, heated to $80{ }^{\circ} \mathrm{C}$, a defined amount of raw aerosol was added to $1.0 \mathrm{l} / \mathrm{min}$ dilution air in the case of the conventional SMPS, resulting in a dilution factor of 28 (reference RDD), or with argon in the case of SMPSICPMS, resulting in a dilution factor of 18 (coupled RDD). The difference of the resulting dilution factors was caused by geometrical differences of the disks of the two RDD devices (Hueglin et al. 1997).

SMPS-ICPMS and conventional SMPS curves correlate very well for both volume-weighted and number-weighted distributions. The number-weighted distributions appear to be shifted a little toward smaller particles compared to the volume-weighted curves, since small particles contribute more to the number concentration and larger particles contribute more to the mass and volume concentration. This is also the reason for the high intensity of the numberrelated ICPMS signal for particles below $15 \mathrm{~nm}$. As mass concentration and thereby ICPMS signal intensity scales with the third power of the particle diameter, ICPMS intensity is much higher for very small particle sizes.

Large agglomerates were found in TEM images of aerosol particles. However, such offline imaging of previous collected particles does not allow distinguishing whether the agglomerates were already present in the aerosol, or if they were formed during particle sampling on the TEM grids, or during sample preparation and storage. Online sampling and SMPSICPMS analysis is better suited for characterizing the size-resolved elemental composition of particles in the aerosol, when they enter the measuring instrumentation directly after spraying. Besides, transient aerosol behavior also becomes visible since the size range scans were repeated every $180 \mathrm{~s}$.

Comparison of suspension and aerosol

For some products, the metals found in the suspension were not detected in the SMPS-ICPMS aerosol measurements, but with TEM-EDX. Fluorine can generally not be detected by ICPMS, because its first ionization energy is higher than that of argon so that it cannot be ionized with argon plasma. For aluminum, which was not detected in the aerosol of spray V, the 
ICPMS has a relatively low intensity due to the use of a collision cell to eliminate mass-based interferences. In spray VI, NP consisting of zinc were detected with TEM-EDX. With the SMPS-ICPMS coupling, this finding was confirmed. Nevertheless, larger particles found by SMPS were not correlated to the ICPMS zinc signal. As discovered by EDX, at larger sizes, the zinc particles were imbedded in fluorine, which apparently shielded them from the ICPMS.

Particle sizes found in the released aerosol were always smaller compared to the particle sizes in the suspensions. This means that during spraying the agglomerates decrease in size or are fully broken to release the primary particles. This result was confirmed by different analytical methods. Spray IV and VI showed the biggest agglomerates in suspension, which broke up into the NP found in the aerosol. In the TEM, these agglomerates looked like raspberries with single particles on the surface, which may be a structure that is easily cleaved during the spray process.

For three products (Spray I, II, and III), large agglomerates containing small primary particles were detected by TEM. The SMPS could not detect these agglomerates as their sizes were exceeding the SMPS measuring range.

After spraying, the aluminum, which had been detected in all six suspensions by SEM-EDX, was only detected in the aerosol of spray V via TEM-EDX. With the SMPS-ICPMS instrumentation, an increase of the aluminum background signal was observed after spraying sprays III, IV, V, and VI, which remained stable on this elevated level for several minutes. So far we have no explanation for the observation of aluminum after spraying. As we observed no corresponding SMPS signal, it is not likely that the ICPMS signal was caused by Al NP in or above the size range scanned by SMPS (bigger particles would not stay in the aerosol phase). A mass interference is not supposed, as Al was measured in the collision mode of the ICPMS. One possible reason could be that this signal was caused by particles $<3 \mathrm{~nm}$, but it is expected that these would have been detected with TEM.

With TEM we found that some of the primary particles were not spherical, which is a phenomenon that had already been observed by Bekker et al. (2014). Since online methods always simplify the calculations by assuming spherical particles for size calculation, it has to be kept in mind that for nonspherical particles the dynamic shape factor has to be determined before calculating the size (Scheuch and Heyder 1990).

\section{Conclusion and outlook}

The purpose of this paper was to define a standard for nanoparticle characterization in sprays and to test different methods for nanoparticle analysis in suspension and in sprays. New methods were tested for both media: spICPMS for suspension analysis and SMPSICPMS coupling for aerosol analysis. Despite the fact that also in future experiments a combination of several methods will be necessary, since there is no perfect single method, spICPMS can be highly recommended for suspension analysis, because it is a fast method and delivers reproducible results, compared to conventional methods such as TEM and DLS. For aerosol analysis, SMPS-ICPMS coupling is a very promising technique. Compared to the conventional methods, it is very fast and delivers the most important data during one online measurement. A drawback, however, is the low detection efficiency of ICPMS for elements with high ionization energy, which is unfavorable e.g. for sprays containing fluorine.

With the new online coupling method, small primary particles can be monitored online and their chemistry can be identified without the generation of artificial agglomerates due to sampling on a TEM grid. Thus, our project is the first to characterize online nanosized aerosols regarding particle size and corresponding composition (Bekker et al. 2014; Chen et al. 2010; Hagendorfer et al. 2010; Lorenz et al. 2011; Nørgaard et al. 2009; Quadros and Marr 2011). The shape of the particles still can only be determined using offline techniques like electron microscopy, so that TEM-EDX should support the method.

To prove the new technique, also suspensions were analyzed with known particle size and concentrations. However, this work will be published by Hess et al. (2015) elsewhere.

In general, a release of NP was observed for all sprays apart from spray I. Hence, not only propellant gas, but also pump sprays can release NP. Therefore, the assumption of Hagendorfer et al. (2010) and Lorenz et al. (2012) that only propellant gas sprays can release NP has to be revisited.

The final size and the agglomeration state of the released particles seem to depend on different factors 
such as the solvent and the formulation. Metals found in the suspensions are the main component of the NP in the released aerosol. Some particles, especially the ones released from impregnation sprays, had a metal core covered by a fluorine-carbon shell. This had already been observed by Lorenz et al. (2012). During the spray process, the size of the initial particles that were present in the suspension decreased: Particles/ Agglomerates present in the suspensions were about 10 times larger than the ones released after application of the sprays. Consequently, also sprays, which are not labeled as nano, may release particles in the nanometer size range. This confirms the results published by Bekker et al. (2014).

For the moment it is difficult to judge if the released particle/metal concentrations pose a real health risk for the consumer, because the toxicological relevance of the nanoform is still under debate. A comparison of the metal concentrations determined in the spray suspension can be done with the concentrations given by the International Conference on Harmonization for elemental impurities in inhalable drugs, which are $0.7 \mu \mathrm{g} / \mathrm{g}$ for $\mathrm{Ag}$ and $6 \mu \mathrm{g} / \mathrm{g}$ for $\mathrm{Sn}$ (ICH 2014). In comparison to these guidance values for bulk material, the concentrations detected in this study are low: The highest detected Ag concentration in suspension was $0.03 \mu \mathrm{g} / \mathrm{g}$ and the highest $\mathrm{Sn}$ concentration $0.4 \mu \mathrm{g} / \mathrm{g}$.

Acknowledgments The authors gratefully acknowledge naneos particle solutions $\mathrm{GmbH}$, and especially Martin Fierz, for providing a portable TEM sampler. We want to thank the Electron Microscopy Center at EMPA for TEM measurements and the Swiss Federal Office of Public Health (FOPH) for financial support (NanoSpray II project).

\section{References}

Al-Kattan A, Wichser A, Vonbank R, Brunner S, Ulrich A, Zuin S, Nowack B (2013) Release of $\mathrm{TiO}_{2}$ from paints containing pigment- $\mathrm{TiO}_{2}$ or nano- $\mathrm{TiO}_{2}$ by weathering. Environ Sci 15(12):2186-2193

Bammes G (2001) Studien zur Gestalt des Menschen: eine Zeichenschule zur Künstleranatomie mit Arbeiten von Laienkünstlern, Kunstpädagogen und Kunststudenten, 2nd edn. Seemann, Leipzig, p 144

Bekker C, Brouwer DH, van Duuren-Stuurman B, Tuinman IL, Tromp P, Fransman W (2014) Airborne manufactured nano-objects released from commercially available spray products: Temporal and spatial influences. J Expo Sci Environ Epidemiol 24:74-81
Benn T, Cavanagh B, Hristovski K, Posner JD, Westerhoff P (2010) The release of nanosilver from consumer products used in the home. J Environ Qual 39(6):1875-1882

Berger-Preiß E, Boehncke A, Könnecker G, Mangelsdorf I, Holthenrich D, Koch W (2005) Inhalational and dermal exposures during spray application of biocides. Int J Hyg Environ Health 208(5):357-372

Berlin K, Dietrich S, Fromme H, Jörres R, Kohlhuber M, Matzen W, Nowak D, Schierl R, Völkel W, Winterhalter R (2011) Endbericht zu den Forschungsprojekten NanoExpo und NanoGesund

BgVV Organozinnverbindungen in Imprägniermitteln für Lederwaren und Textilien. http://www.bfr.bund.de/cm/343/ organozinnverbindungen_in_impraegniermitteln_fuer_ lederwaren_und_textilien.pdf. Accessed 03 Sep 2014

Brzeziński S, Malinowska G, Kowalczyk D, Kaleta A, Borak B, Jasiorski M, Dabek K, Baszczuk A, Tracz A (2012) Antibacterial and fungicidal coating of textile-polymeric materials filled with bioactive nano-and submicro-particles. Fibres Text East Eur 90(1):70-77

Chen X, Schluesener HJ (2008) Nanosilver: a nanoproduct in medical application. Toxicol Lett 176(1):1-12

Chen BT, Afshari A, Stone S, Jackson M, Schwegler-Berry D, Frazer DG, Castranova V, Thomas TA (2010) Nanoparticles-containing spray can aerosol: Characterization, exposure assessment, and generator design. Inhal Toxicol 22(13):1072-1082

FORS COMPASS, Swiss Health Survey (SHS) (2007). http:// compass-data.unil.ch/SGB-Documentation/SGB-ESS\% 202007\%20COMPASS\%20Codebook\%20E.pdf. Accessed 11 June 2015

Graf BW, Chaney EJ, Marjanovic M, De Lisio M, Valero MC, Boppart MD, Boppart SA (2013) In vivo imaging of immune cell dynamics in skin in response to zinc-oxide nanoparticle exposure. Biomed Opt Express 4(10):1817-1828

Hagendorfer H, Lorenz C, Kaegi R, Sinnet B, Gehrig R, Goetz N, Scheringer M, Ludwig C, Ulrich A (2010) Size-fractionated characterization and quantification of nanoparticle release rates from a consumer spray product containing engineered nanoparticles. J Nanopart Res 12(7):24812494

Hall B, Tozer S, Safford B, Coroama M, Steiling W, LeneveuDuchemin MC, McNamara C, Gibney M (2007) European consumer exposure to cosmetic products, a framework for conducting population exposure assessments. Food Chem Toxicol 45(11):2097-2108

Hess A, Mohamed T, Ludwig C (2015) A hyphenated SMPSICPMS coupling setup: size-resolved element specific analysis of airborne nanoparticles. J Aerosol Sci. doi:10. 1016/j.jaerosci.2015.05.016

Hueglin C, Scherrer L, Burtscher H (1997) An accurate, continuously adjustable dilution system $(1: 10$ to $1: 104)$ for submicron aerosols. J Aerosol Sci 28(6):1049-1055

ICH International Conference on Harmonisation of technical requirements for registration of pharmaceuticals for human use: guideline for elemental impurities, Q3D (2014). http:// www.ich.org/fileadmin/Public_Web_Site/ICH_Products/ Guidelines/Quality/Q3D/Q3D_Step_4.pdf. Accessed 01 April 2015

Kaegi R, Sinnet B, Zuleeg S, Hagendorfer H, Mueller E, Vonbank R, Boller M, Burkhardt M (2010) Release of silver 
nanoparticles from outdoor facades. Environ Pollut 158(9):2900-2905

Krug HF, Wick P (2011) Nanotoxicology: an interdisciplinary challenge. Angew Chem 50(6):1260-1278

Lorenz C, Hagendorfer H, von Goetz N, Kaegi R, Gehrig R, Ulrich A, Scheringer M, Hungerbuhler K (2011) Nanosized aerosols from consumer sprays: experimental analysis and exposure modeling for four commercial products. J Nanopart Res 13(8):3377-3391

Lorenz C, Windler L, von Goetz N, Lehmann RP, Schuppler M, Hungerbühler K, Heuberger M, Nowack B (2012) Characterization of silver release from commercially available functional (nano)textiles. Chemosphere 89(7):817-824

Losert S, von Goetz N, Bekker C, Fransman W, Wijnhoven SWP, Delmaar C, Hungerbuhler K, Ulrich A (2014) Human exposure to conventional and nanoparticle-containing sprays - a critical review. Environ Sci Technol 48(10):5366-5378

Malvern, Z (2004) Nano Series User Manual. Malvern Instruments

Nørgaard AW, Jensen KA, Janfelt C, Lauritsen FR, Clausen PA, Wolkoff P (2009) Release of VOCs and particles during use of nanofilm spray products. Environ Sci Technol 43(20):7824-7830

Nørgaard AW, Larsen ST, Hammer M, Poulsen SS, Jensen KA, Nielsen GD, Wolkoff P (2010) Lung damage in mice after inhalation of nanofilm spray products: the role of perfluorination and free hydroxyl groups. Toxicol Sci 116(1): 216-224

Oomen A, Bennink M, Engelen JV, Sips A (2011) Nanomaterials in consumer products-Detection, characterization and interpretation. http://www.rivm.nl/bibliotheek/rapporten/ 320029001.html. Accessed 12 June 2013

Quadros ME, Marr LC (2011) Silver nanoparticles and total aerosols emitted by nanotechnology-related consumer spray products. Environ Sci Technol 45(24):10713-10719

Rühli F, Henneberg M, Woitek U (2008) Variability of height, weight, and body mass index in a Swiss armed forces 2005 census. Am J Phys Anthropol 137(4):457-468
Scheuch G, Heyder J (1990) Dynamic shape factor of nonspherical aerosol particles in the diffusion regime. Aerosol Sci Technol 12(2):270-277

Schneider T, Brouwer DH, Koponen IK, Jensen KA, Fransman W, Van Duuren-Stuurman B, Van Tongeren M, Tielemans E (2011) Conceptual model for assessment of inhalation exposure to manufactured nanoparticles. J Expo Sci Environ Epidemiol 21(5):450-463

Skocaj M, Filipic M, Petkovic J, Novak S (2011) Titanium dioxide in our everyday life; is it safe? Radiol Oncol 45(4):227-247

Statistisches_Bundesamt Ergebnisse des Mikrozensus (2009) https://www.destatis.de/DE/ZahlenFakten/GesellschaftStaat/ Gesundheit/GesundheitszustandRelevantesVerhalten/ Tabellen/Koerpermasse.html?nn=50798 Accessed 08 Dec 2014

Sung JH, Ji JH, Yoon JU, Kim DS, Song MY, Jeong J, Han BS, Han JH, Chung YH, Kim J, Kim TS, Chang HK, Lee EJ, Lee JH, Yu IJ (2008) Lung function changes in SpragueDawley rats after prolonged inhalation exposure to silver nanoparticles. Inhal Toxicol 20(6):567-574

von Goetz N, Fabricius L, Glaus R, Weitbrecht V, Günther D, Hungerbühler K (2013) Migration of silver from commercial plastic food containers and implications for consumer exposure assessment. Food Addit Contam 30(3): $612-620$

Woodrow Wilson Project on Emerging Nanotechnologies. http://www.nanotechproject.org. Accessed 04 Oct 2012

Xue CH, Chen J, Yin W, Jia ST, Ma JZ (2012) Superhydrophobic conductive textiles with antibacterial property by coating fibers with silver nanoparticles. Appl Surf Sci 258(7):2468-2472

Zhu R, Zhao W, Zhai M, Wei F, Cai Z, Sheng N, Hu Q (2010) Molecularly imprinted layer-coated silica nanoparticles for selective solid-phase extraction of bisphenol A from chemical cleansing and cosmetics samples. Anal Chim Acta 658(2):209-216 